\title{
Influence of the Variable-Speed Wind Generators in Transient Stability Margin of the Conventional Generators Integrated in Electrical Grids
}

\author{
Marcus V. A. Nunes, J. A. Peças Lopes, Senior Member, IEEE, Hans Helmut Zürn, Member, IEEE, \\ Ubiratan H. Bezerra, and Rogério G. Almeida
}

\begin{abstract}
This work demonstrates that the integration of variable-speed wind systems with doubly fed induction generators (DFIGs) and a four-quadrant ac-to-ac converter connected to the rotor windings increases the transient stability margin of the electrical grids, when compared with the case where the fixed speed wind systems with cage generators are used. It is due to the influence of the two dedicated rotor current regulators of the DFIG on the dynamic behavior of the other generators in the system. Besides, adequate models to represent the behavior of the DFIG in transient stability studies are presented. From the simulation results, some important conclusions can be extracted to guide the integration of the wind farms on weak or strong grids.
\end{abstract}

Index Terms-Decoupled control, doubly fed induction generator (DFIG) protection, electrical grids, fixed speed wind systems, transient stability margin, variable-speed wind systems.

\section{INTRODUCTION}

$\mathbf{I}$ N RECENT YEARS, there has been a widespread growth in the exploitation of wind energy, which required the development of larger and more robust wind energy conversion systems (WECS). Requirements in terms of power controllability during normal operation to allow some degree of control over reactive power and active power production and in the event of grid abnormalities (e.g., grid faults) have increased, leading to the development of a new generation of WECS - the variable-speed wind generating systems with doubly fed induction machines [1], [2].

The configurations of variable-speed generation that employ a doubly fed induction generator (DFIG) with a four-quadrant ac-to-ac converter connected to the rotor windings, present noticeable advantages such as the decoupled control of active and reactive power of the generator, the improvement of system efficiency, and the fact that the rotor power converter only needs to handle a fraction (25-30\%) of the total power to achieve full control of the generator [2]. The rotor converter uses a highfrequency switching pulsewidth-modulated (PWM) converter to achieve high control performance, such as fast dynamic response with low harmonic distortion.

Manuscript received June 27, 2003. This work was supported in part by CAPES (Brazil) and in part by the Portuguese FCT Project POCTI/ESE/ 41614/2001-Diptune. Paper no. TEC-00160-2003.

The authors are with the Federal University of Para (UFPA), Belém-PA 66075-900, Brazil (e-mail: mvan@ufpa.br).

Digital Object Identifier 10.1109/TEC.2004.832078
Furthermore, with this control strategy, the induction generator can operate with a comparatively wide slip range, which allows making better use of the available wind energy, [3]. With the perspective of increased penetration of WECS in the electrical networks [4]-[6], it is most important to keep these generators in the grid, following network disturbances, contributing to improve the global system dynamic behavior. Up to now, WECS have been designed to be disconnected fast from the grid if a large voltage dip occurs. This may happen as a result of a large network disturbance, such as a short circuit, and may trigger a sequence of other events leading to local voltage problems and eventually to a power outage in a large portion of the system.

Therefore, to obtain an optimal integration of wind energy in the system, the large wind farms must be able to withstand network disturbances that are successfully eliminated (i.e., be able to participate in the control and stabilization of the power system following system disturbances). The DFIG concept may represent an excellent possibility to improve network dynamic behavior.

The main objectives of this paper are: a) to demonstrate that the DFIG can be used to maintain system stability following system disturbances; b) to show that adequate WECS modeling is needed to get a consistent dynamic evaluation behavior from the network side. In order to do that, the fundamental WECS dynamics and its protection behavior should be taken into consideration in the modeling development. Two models for the DFIG rotor converters have been tested here: a current-controlled voltage source model and a current source model. These models were implemented with a dedicated dynamic power system simulation software package, using MATLAB, with a friendly user interface [7].

The results obtained from dynamic simulations show that an increase in the global transient stability margin of the grid can be obtained when the DFIGs are integrated in the system, namely regarding the case where the fixed speed wind turbine with cage generator is employed.

Modeling related to the aerodynamic and mechanical aspects of the wind turbine and the generator are presented in Section II. A decoupled control between the electrical torque and the excitation rotor current of the DFIG is presented in Section III. Section IV presents the converter protection adopted here for the DFIG. The results for grid faults simulated on a sample power system are presented in Section V. 


\section{Wind TURBINE AND GENERATOR MODELS}

The first stage in the simulation process is to model individual system components with an appropriate degree of complexity. In the following subsections, dynamic wind turbine and generator models used to represent the wind driven systems in dynamic stability studies are described.

\section{A. Model of the Rotating Turbine}

The wind turbine aerodynamics can be characterized by the well-known nondimensional curves of the power coefficient $\mathrm{C}_{\mathrm{p}}$ as a function of both tip speed ratio $\lambda$ and the blade pitch angle $\beta$ [4]. The tip speed ratio is the ratio between the blade tip speed $\mathrm{v}_{\mathrm{t}}$ and the wind speed $\mathrm{U}_{\mathrm{w}}$

$$
\lambda=\frac{\mathrm{v}_{\mathrm{t}}}{\mathrm{U}_{\mathrm{w}}} .
$$

Using the coefficient $\mathrm{C}_{\mathrm{p}}$, the aerodynamic power $\mathrm{P}_{\mathrm{ae}}$ of the turbine is determined by

$$
\mathrm{P}_{\mathrm{ae}}=\frac{1}{2} \rho \pi \mathrm{R}^{2} \mathrm{v}_{\mathrm{t}}^{3} \mathrm{C}_{\mathrm{p}}(\lambda, \beta)
$$

where $\rho$ is the air density $\left(\mathrm{kg} / \mathrm{m}^{3}\right)$.

Combining (1) and (2), the torque available from the wind turbine $T_{t}$ is determined directly from the aerodynamic power according to:

$$
\mathrm{T}_{\mathrm{t}}=\frac{\mathrm{P}_{\mathrm{ae}}}{\omega_{\mathrm{r}}}=\frac{\pi}{2 \lambda} \rho \mathrm{R}^{3} \mathrm{v}_{\mathrm{t}}^{2} \mathrm{C}_{\mathrm{p}}(\lambda, \beta) .
$$

The power extracted from the wind is maximized if the rotor speed is such that $\mathrm{C}_{\mathrm{p}}$ is maximum. The shape of the $\mathrm{C}_{\mathrm{p}}-\lambda$ curve has a significant influence on energy capture. The $\mathrm{C}_{\mathrm{p}}-\lambda$ curve from experimental results of the manufacturers of a turbine of $660 \mathrm{~kW}$ used here is shown in Fig. 1 [7].

The variable-speed wind system used adjusts the turbine speed as a function of wind speed to maximize output power. Operation at the maximum power point can be realized over a wide power range. Fig. 2 illustrates the output power-speed curves as a function of turbine speed and wind speed for the $660-\mathrm{kW}$ turbine. These curves were obtained from the blade element momentum method (BEM) [6], [7].

A control strategy is therefore applied to follow $\mathrm{P}_{\text {opt }}$, given by (4) which leads to the maximum energy capture. The main control objective is to optimize the efficiency of wind energy capture in a wide range of wind velocities, keeping the power generated by the machine constant and equal to the optimal defined value.

Since the rotor speed $\omega_{\mathrm{r}}$ is proportional to the wind speed, the power increases with $\omega_{\mathrm{r}}^{3}$ and the corresponding generator torque with $\omega_{\mathrm{r}}^{2}$. The optimal characteristic for the model can then be defined for power and torque by [2]

$$
\mathrm{P}_{\mathrm{opt}}=\mathrm{K}_{\mathrm{opt}} \omega_{\mathrm{r}}^{3} \quad \text { and } \quad \mathrm{T}_{\text {Popt }}=\mathrm{K}_{\text {Popt }} \omega_{\mathrm{r}}^{2} .
$$

For wind velocities higher than rated, the turbine energy capture must be limited by applying pitch control and for velocities below rated, the machine follows (4). The optimal generator rotor speed $\left(\omega_{\mathrm{r}, \text { ref }}\right)$ obtained from the power-speed curves shown in Fig. 2, serves as a dynamic reference for the speed

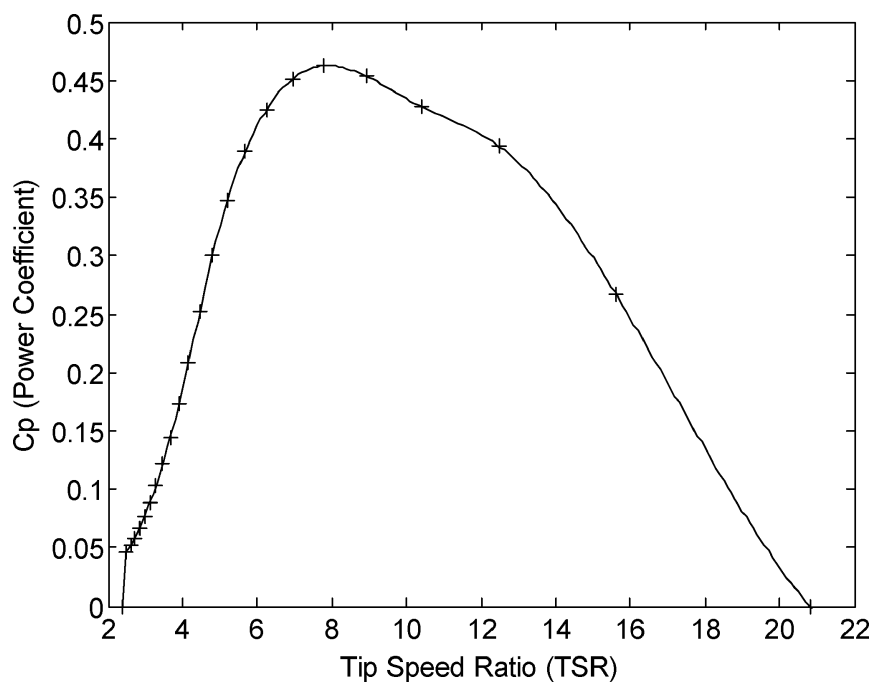

Fig. 1. Curve $\mathrm{C}_{\mathrm{p}}$ (power coefficient) $\times \lambda$ (tip speed ratio)

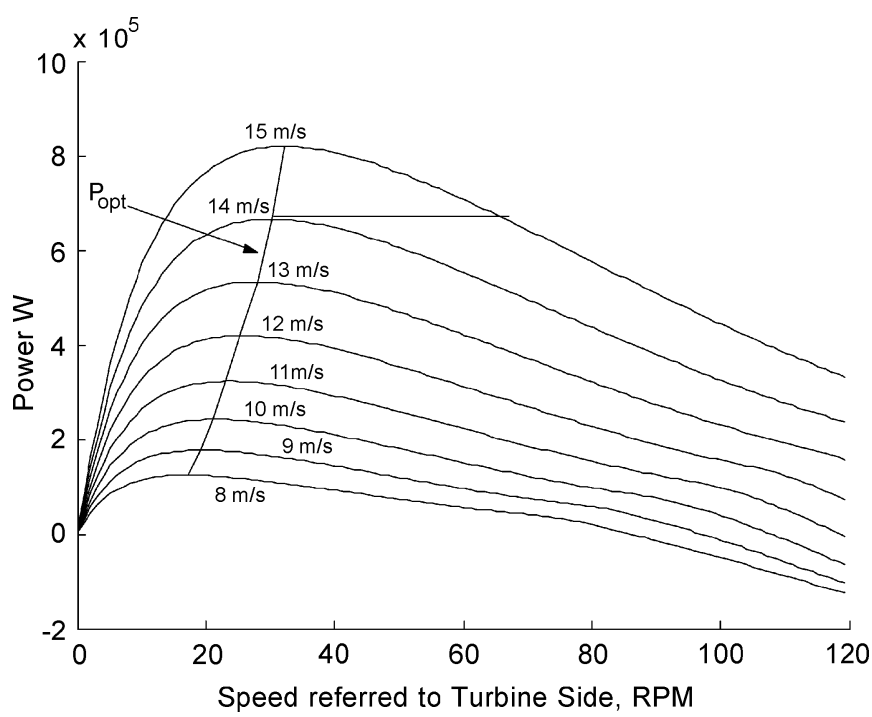

Fig. 2. Electrical output power as a function of turbine speed.

control loop of the doubly fed generator shown in Figs. 5 and 6 of the DFIG control.

\section{B. Induction Generator Model}

For the fixed speed wind systems with cage induction generators a third-order (rotor flux transient) dynamic model based on the theory of rotating fields and the $d-q$ coordinate system is used here to represent the induction generator connected to the grid [9].

The adjustable speed generator (DFIG) has a structure similar to a wound rotor induction machine using slip rings to allow current into or out of the rotating secondary winding. To enable dynamic modeling of the DFI-based wind turbine under different wind speeds, it is important to understand the required configuration of the system and to consider that this kind of machine has to be fed from both the rotor and stator sides [10], [11].

A wind converter system with a DFIG and a bidirectional power converter is shown in Fig. 3. The system has typically two ac/dc insulated-gate bipolar transistor (IGBT) four-quadrant power converters linked by a dc bus [2], [3]. In this scheme, 


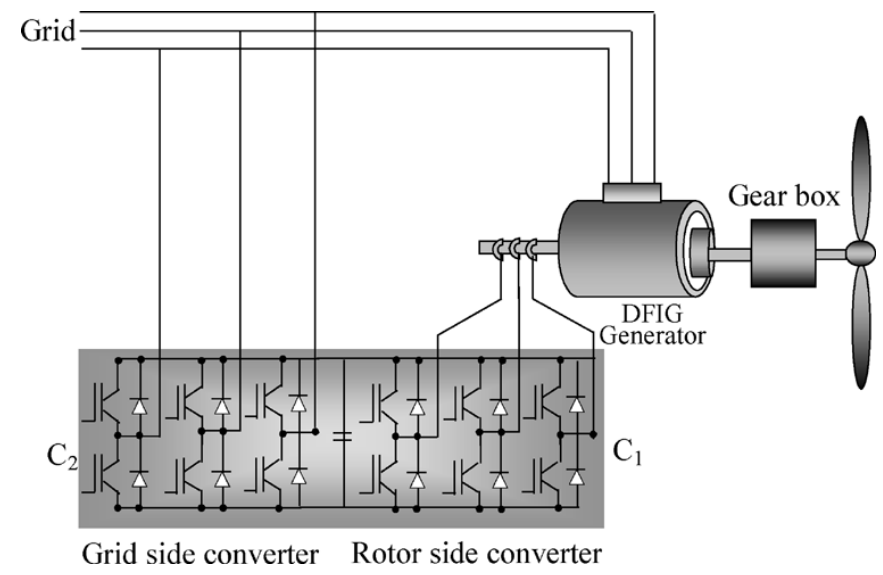

Fig. 3. Wind system with a DFIG.

converters decouple the rotational speed of the generator from the frequency of the grid enabling variable-speed operation of the wind turbine.

Here it is assumed that the objective of the supply-side converter is to keep the dc-link voltage constant providing a path for rotor power to and from the ac system at a unity power factor. The rotor side converter $\mathrm{C}_{1}$ controls rotor current in order to maintain the stator voltage and the maximum electromagnetic (EM) torque of the machine. In this model, the dc link voltage is considered constant. With this, the exchange of reactive power with the grid is completely performed through the stator of the generator.

The asynchronous machine equations are derived from Park's equations for a two axis $d-q$ reference system rotating at synchronous speed, using generator convention, which means that the stator currents are positive when flowing toward the network and real and reactive powers are positive when fed into the grid. The following set of ordinary differential equations results for a DFIG machine:

$$
\begin{aligned}
& \mathrm{v}_{\mathrm{ds}}=-\mathrm{R}_{\mathrm{s}} \mathrm{i}_{\mathrm{ds}}-\omega_{\mathrm{s}} \psi_{\mathrm{qs}}+\frac{\mathrm{d} \psi_{\mathrm{ds}}}{\mathrm{dt}} \\
& \mathrm{v}_{\mathrm{qs}}=-\mathrm{R}_{\mathrm{s}} \mathrm{i}_{\mathrm{qs}}+\omega_{\mathrm{s}} \psi_{\mathrm{ds}}+\frac{\mathrm{d} \psi_{\mathrm{qs}}}{\mathrm{dt}} \\
& \mathrm{v}_{\mathrm{dr}}=-\mathrm{R}_{\mathrm{r}} \mathrm{i}_{\mathrm{dr}}-\left(\omega_{\mathrm{s}}-\omega_{\mathrm{r}}\right) \psi_{\mathrm{qr}}+\frac{\mathrm{d} \psi_{\mathrm{dr}}}{\mathrm{dt}} \\
& \mathrm{v}_{\mathrm{qr}}=-\mathrm{R}_{\mathrm{r}} \mathrm{i}_{\mathrm{qr}}+\left(\omega_{\mathrm{s}}-\omega_{\mathrm{r}}\right) \psi_{\mathrm{dr}}+\frac{\mathrm{d} \psi_{\mathrm{qr}}}{\mathrm{dt}}
\end{aligned}
$$

with $\mathrm{v}$ being the voltage $(\mathrm{V}), \mathrm{R}$ is the resistance $(\Omega)$, $\mathrm{i}$ is the current (A), $\omega_{\mathrm{s}}$ and $\omega_{\mathrm{r}}$ is the stator and rotor electrical frequency $(\mathrm{rad} / \mathrm{s}), \psi$ the flux linkage (Vs), s the rotor slip, ds, dr, and qs, qr correspond to $d$-axis stator and rotor and q-axis stator and rotor indices, respectively.

The per-unit EM torque of the DFIG can be expressed by

$$
\mathrm{T}_{\mathrm{e}}=\Psi_{\mathrm{qr}} \mathrm{i}_{\mathrm{dr}}-\Psi_{\mathrm{dr}} \dot{\mathrm{i}}_{\mathrm{qr}} \cdot
$$

The change in generator speed that results from the difference between electrical and mechanical torque can be calculated using the generator equation of motion

$$
\frac{\mathrm{d} \omega}{\mathrm{dt}}=\frac{1}{2 \mathrm{H}}\left(\mathrm{T}_{\mathrm{m}}-\mathrm{T}_{\mathrm{e}}\right)
$$

where $\mathrm{H}$ is the inertia constant (s) and $\mathrm{T}_{\mathrm{m}}$ is the mechanical torque.

Considering the grid side of the converter operating at unity power factor, the reactive power at the stator of the DFIG varies with the stator currents as follows:

$$
\mathrm{Q}_{\text {stator }}=\mathrm{v}_{\mathrm{qs}} \mathrm{i}_{\mathrm{ds}}-\mathrm{v}_{\mathrm{ds}} \mathrm{i}_{\mathrm{qs}} \text {. }
$$

Since the stator transients are very fast, when compared with the rotor ones, it is possible to neglect them. This corresponds to ignoring the dc component in the stator transient current, enabling representation of only fundamental frequency components. By substitution of the flux linkage equations to eliminate the rotor currents, a relationship of the stator and rotor voltages in terms of a voltage behind a transient reactance is obtained. The stator and rotor voltages are derived in the following per-unit form:

$$
\begin{aligned}
\mathrm{v}_{\mathrm{ds}} & =-\mathrm{R}_{\mathrm{s}} \mathrm{i}_{\mathrm{ds}}+\mathrm{X}^{\prime} \mathrm{i}_{\mathrm{qs}}+\mathrm{v}_{\mathrm{d}}^{\prime} \\
\mathrm{v}_{\mathrm{qs}} & =-\mathrm{R}_{\mathrm{s}} \mathrm{i}_{\mathrm{qs}}-\mathrm{X}^{\prime} \mathrm{i}_{\mathrm{ds}}+\mathrm{v}_{\mathrm{q}}^{\prime} \\
\frac{\mathrm{dv}_{\mathrm{d}}^{\prime}}{\mathrm{dt}} & =-\frac{1}{\mathrm{~T}_{\mathrm{o}}}\left[\mathrm{v}_{\mathrm{d}}^{\prime}+\left(\mathrm{X}-\mathrm{X}^{\prime}\right) \mathrm{i}_{\mathrm{qs}}\right]-\mathrm{s} \omega_{\mathrm{s}} \mathrm{v}_{\mathrm{q}}^{\prime}+\omega_{\mathrm{s}} \frac{\mathrm{L}_{\mathrm{m}}}{\mathrm{L}_{\mathrm{rr}}} \mathrm{v}_{\mathrm{qr}} \\
\frac{\mathrm{dv}_{\mathrm{q}}^{\prime}}{\mathrm{dt}} & =-\frac{1}{\mathrm{~T}_{\mathrm{o}}}\left[\mathrm{v}_{\mathrm{q}}^{\prime}+\left(\mathrm{X}-\mathrm{X}^{\prime}\right) \mathrm{i}_{\mathrm{ds}}\right]-\mathrm{s} \omega_{\mathrm{s}} \mathrm{v}_{\mathrm{d}}^{\prime}+\omega_{\mathrm{s}} \frac{\mathrm{L}_{\mathrm{m}}}{\mathrm{L}_{\mathrm{rr}}} \mathrm{v}_{\mathrm{dr}} .
\end{aligned}
$$

The components of the internal voltage behind the transient reactance are defined as [8], [10]

$$
\begin{aligned}
& \mathrm{v}_{\mathrm{d}}^{\prime}=-\frac{\omega_{\mathrm{s}} \mathrm{L}_{\mathrm{m}}}{\mathrm{L}_{\mathrm{rr}}} \psi_{\mathrm{qr}} \\
& \mathrm{v}_{\mathrm{q}}^{\prime}=\frac{\omega_{\mathrm{s}} \mathrm{L}_{\mathrm{m}}}{\mathrm{L}_{\mathrm{rr}}} \psi_{\mathrm{dr}} .
\end{aligned}
$$

New reactances and the transient open-circuit time constant are given by

$$
\begin{aligned}
\mathrm{X}^{\prime} & =\omega_{\mathrm{s}}\left[\mathrm{L}_{\mathrm{ss}}-\frac{\mathrm{L}_{\mathrm{m}}^{2}}{\mathrm{~L}_{\mathrm{rr}}}\right]=\mathrm{X}_{\mathrm{s}}+\frac{\mathrm{X}_{\mathrm{r}} \mathrm{X}_{\mathrm{m}}}{\mathrm{X}_{\mathrm{r}}+\mathrm{X}_{\mathrm{m}}} \\
\mathrm{X} & =\omega_{\mathrm{s}} \mathrm{L}_{\mathrm{ss}}=\mathrm{X}_{\mathrm{s}}+\mathrm{X}_{\mathrm{m}} \\
\mathrm{T}_{\mathrm{o}} & =\frac{\mathrm{L}_{\mathrm{rr}}}{\mathrm{R}_{\mathrm{r}}}=\frac{\mathrm{L}_{\mathrm{r}}+\mathrm{L}_{\mathrm{m}}}{\mathrm{R}_{\mathrm{r}}}
\end{aligned}
$$

where $\mathrm{L}_{\mathrm{ss}}=\mathrm{L}_{\mathrm{m}}+\mathrm{L}_{\mathrm{s}}, \mathrm{L}_{\mathrm{rr}}=\mathrm{L}_{\mathrm{m}}+\mathrm{L}_{\mathrm{r}}$ and Lm, Ls, and $\mathrm{L}_{\mathrm{r}}$ are the mutual, stator, and rotor leakage inductances, respectively.

In this formulation, the dynamic of the rotor is considered and the converters are modeled as current-controlled voltage sources. The voltages $\mathrm{v}_{\mathrm{d}}^{\prime}$ and $\mathrm{v}_{\mathrm{q}}^{\prime}$, defined by (14) and (15) for the DFIG contain an additional element, the direct $\mathrm{v}_{\mathrm{dr}}$ and quadrature $\mathrm{v}_{\mathrm{qr}}$ components of the rotor voltage, compared to the cage induction generators from fixed speed wind systems. This results from the fact that the rotor voltages of the DFIG are nonzero due to the possibility of a potential voltage difference across the slip rings of the machine.

Alternatively, it is possible to omit the inner current control loop of the converters in transient stability studies due to the fact that the action of these controllers is much faster (milliseconds) than the speed and voltage-control loop of the DFIG [11]. Therefore, it is also possible to model the converters as a current source. This interacts with the rotor steady-state conditions 


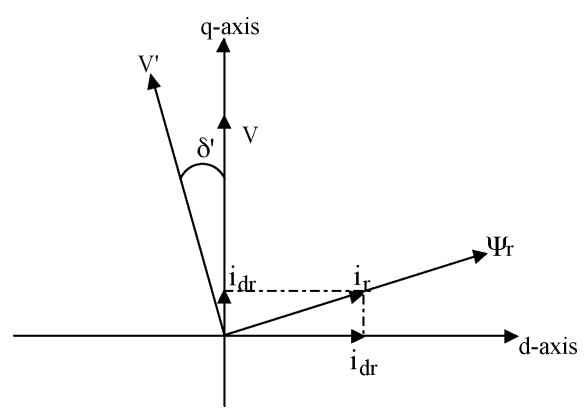

Fig. 4. Vector diagram of the DFIG.

once the flux derivatives are made equal to zero. This is equivalent to directly controlling the rotor fluxes, because there is now an algebraic relation between the rotor fluxes and currents. In this case, the stator voltage equations are written as below. The stator and rotor current equations will be presented in the next section jointly with the control loops

$$
\begin{aligned}
& \mathrm{v}_{\mathrm{ds}}=-\mathrm{R}_{\mathrm{s}} \mathrm{i}_{\mathrm{ds}}+\mathrm{Xi}_{\mathrm{qs}}+\mathrm{X}_{\mathrm{m}} \mathrm{i}_{\mathrm{qr}} \\
& \mathrm{v}_{\mathrm{qs}}=-\mathrm{R}_{\mathrm{s}} \mathrm{i}_{\mathrm{qs}}-\mathrm{Xi}_{\mathrm{ds}}-\mathrm{X}_{\mathrm{m}} \mathrm{i}_{\mathrm{dr}} .
\end{aligned}
$$

\section{Aggregated Wind Farm Model}

An aggregated wind farm model should be used for system dynamic behavior analysis in order to reduce problem dimension and complexity. In this case, the wind park can be partitioned into groups of $n$ equal machines, which operate identically and an equivalent machine can then replace each group [12]. The parameters of the equivalent wind machine replacing $n$-machines operating identically are then given by the relations stated in references [11] and [13].

\section{DeCoupled Control System}

The main aspects related to the control of the DFIG will be exposed in this section. Two decoupled closed-loop controllers are responsible for the control of the reactive power or voltage and the active power or EM torque. The two possible forms of modeling the rotor converters (i.e., two current-controlled voltage source or a single current source will be described in the subsections that follow.)

\section{A. Performance of the Control With the Converters as Current-Controlled Voltage Source}

If the dynamics of the rotor is considered, the excitation control system of doubly fed machines will be considered with two levels of controllers: Rotor current controller in an inner level and both voltage and speed controllers at the outer level. In this case, the magnitude and phase of the internal voltage of the rotating machine can then be controlled within a specified range of rotor speed by changing $d$ - and $q$-axis components of the rotor current vector with the two-excitation controllers.

The vector diagram of voltages, flux, and currents expressed in $d$ - and $q$-axis coordinates is shown in Fig. 4 . In this case, $\mathrm{v}^{\prime}$ representing the resulting internal voltage is $\delta^{\prime}$ ahead in phase from the terminal voltage $\mathrm{v}$, indicating generating operation.

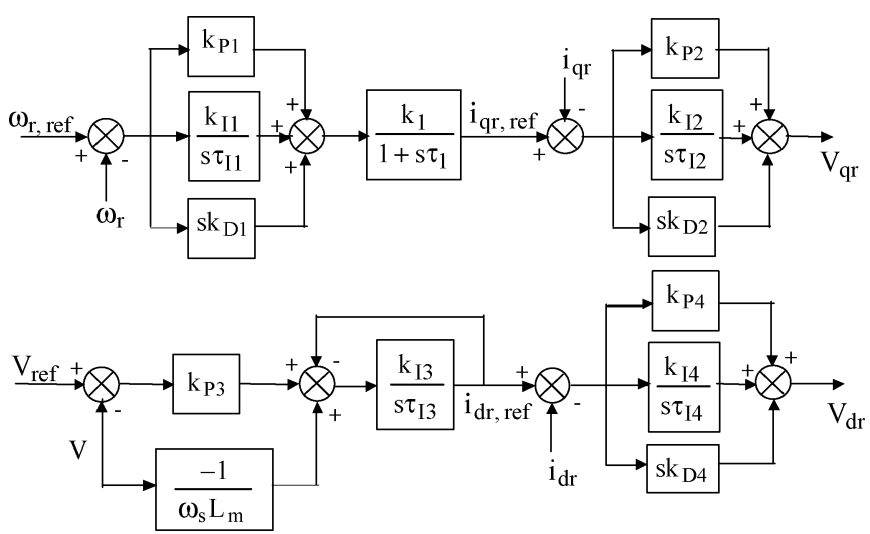

Fig. 5. Control of the DFIG with the converters as voltage sources.

The flux linkage vector in the rotor circuit $\Psi_{r}^{\prime}$ is located $90^{\circ}$ behind the internal voltage vector.

Considering that the phase angle $\delta^{\prime}$ is relatively small, the magnitude of vector of the rotor circuit current $i_{r}$ can be changed effectively by changing the $d$-axis component of the rotor circuit current $\mathrm{i}_{\mathrm{dr}}$. Similarly, changing the $q$-axis component of the rotor circuit current can change the phase of the rotor circuit current. Thus, the voltage or reactive power control can be realized by changing the $d$-axis component of the rotor circuit voltage, and speed or torque control can be realized by changing the $q$-axis component of the rotor circuit voltage.

The two levels of controllers of the DFIG are shown in Fig. 5. The speed controller compares the actual with the optimal rotor reference speed $\left(\omega_{\mathrm{r}, \mathrm{ref}}\right)$. Those controllers are composed of elements of proportional, integral, and derivative transfer functions (PID). The model parameters of the speed, voltage, and current controllers were obtained from [11].

\section{B. Rotor-Side Converter Simulated as Current Source}

This model assumes that the converter is able to control the rotor currents to follow the reference values at all times. In this case, it is assumed that $i_{d r}=i_{d r}$,ref and $i_{q r}=i_{q r, r e f .}$. To be able to decouple the control of active and reactive power in the rotor, the DFIG is also controlled in a synchronously rotating $d-q$ axis frame, with the $d$-axis oriented along the stator flux $\left(\psi_{\mathrm{s}}\right)$ vector position. This means that the flux linkage with the stator in the $q$-axis corresponds to

$$
\psi_{\mathrm{qs}}=-\mathrm{L}_{\mathrm{s}} \mathrm{i}_{\mathrm{qs}}-\mathrm{L}_{\mathrm{m}} \mathrm{i}_{\mathrm{qr}}=0
$$

when the $d$-axis stator flux linkage is found, the $q$-axis stator current can be calculated as $\mathrm{i}_{\mathrm{qs}}=-\left(\mathrm{L}_{\mathrm{m}} / \mathrm{L}_{\mathrm{s}}\right) \mathrm{i}_{\mathrm{qr}}$.

Based on (5) to (8), considering the flux linkages with the stator and rotor, maintaining the previous reference frame and additionally taking into account that the influence of the stator resistance is small, the per-unit EM torque can be expressed in decoupled form as a function of the $q$-rotor current component $\left(i_{\mathrm{qr}}\right)$ and terminal voltage as

$$
\mathrm{T}_{\mathrm{e}}=-\frac{\mathrm{L}_{\mathrm{m}} \mathrm{V}}{\mathrm{L}_{\mathrm{s}}+\mathrm{L}_{\mathrm{m}}} \mathrm{i}_{\mathrm{qr}} \text {. }
$$

The EM torque control consists of a speed control loop. The aim of the loop is to modify the EM torque of the generator 


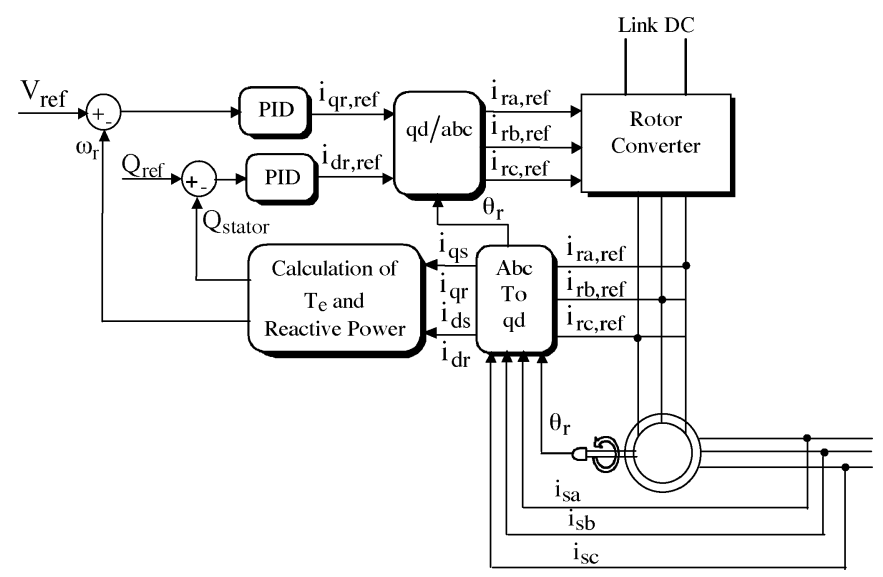

Fig. 6. Vector control of the DFIG with converter as current source.

according to speed variations. By acting upon the rotor side of converter $\mathrm{C}_{1}$, its purpose is to drive the system to the required operating point reference by the adopted control strategy. As stated above, this may be obtained by setting a speed reference that the system must follow. The speed error then determines the $q$ reference current $\mathrm{i}_{\mathrm{qr}}$ by means of a PID controller. The implementation of this control scheme linked with the rotor machine is shown in Fig. 6.

From (11) and considering the flux linkage with the stator $d$-axis, the following expression is obtained for the total grid side reactive power as a function of the $d$-axis rotor current and terminal voltage:

$$
\mathrm{Q}_{\text {stator }}=-\mathrm{v}\left(\frac{\mathrm{v}+\omega_{\mathrm{s}} \mathrm{L}_{\mathrm{m}} \mathrm{i}_{\mathrm{dr}}}{\omega_{\mathrm{s}}\left(\mathrm{L}_{\mathrm{m}}+\mathrm{L}_{\mathrm{S}}\right)}\right)
$$

The reactive power control loop adopted here compares the reactive power at the stator with the reference value $\left(\mathrm{Q}_{\mathrm{ref}}\right)$, before sending the deviation signal to a controller. The output signal of the PID control in this case is the $d$-axis rotor current, idr, as shown in Fig. 6. The $d$ - and $q$-axis rotor currents are transformed to three-phase currents before being applied to the rotor side converter.

The $d$-axis rotor current controls the reactive power. The stator magnetizing current and the flux linkage can be considered constant when the stator is connected to the grid and the influence of the stator resistance is small. When a change occurs in the $d$-axis rotor current, the current at the stator, ids, will change. Because the flux linkage can be considered constant, the d-axis stator current is dependent on the rotor currents and the inductances $\mathrm{L}_{\mathrm{s}}$ and $\mathrm{L}_{\mathrm{m}}$, as follows:

$$
\mathrm{i}_{\mathrm{ds}}=\frac{\psi_{\mathrm{ds}}-\mathrm{i}_{\mathrm{dr}} \mathrm{L}_{\mathrm{m}}}{\mathrm{L}_{\mathrm{s}}}
$$

\section{Protection OF THE DFIG}

A major drawback when using grid-connected power converters is their sensitivity to grid disturbances. Faults in the power system, machine, or converter devices may result in high currents, which to avoid damages, can lead to the forced outage of the turbine [14]. Since the stator-to-rotor turns ratio of the

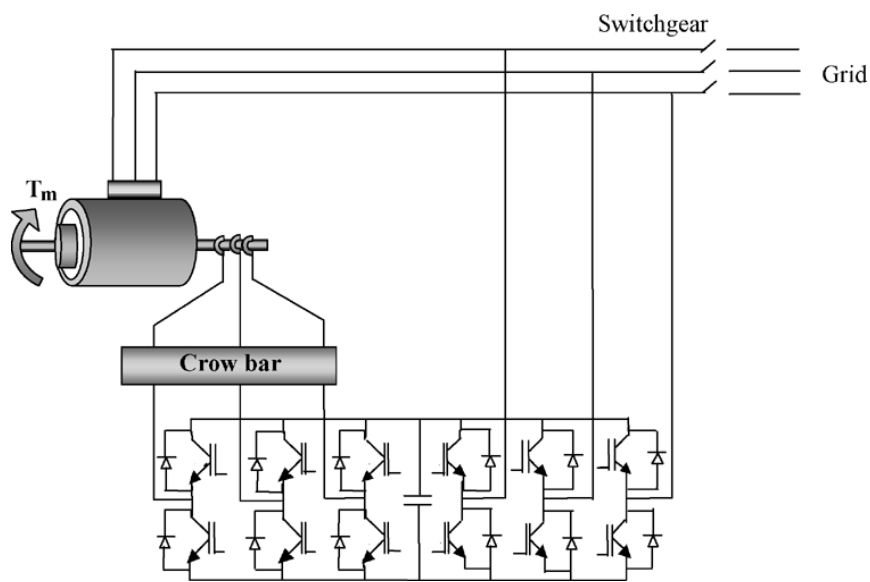

Fig. 7. DFIG circuit.

DFIG is designed according to the desired variable-speed range and the maximum rotor voltage is in the interval of \pm 0.35 p.u, it might not be possible to achieve the desired rotor voltage in order to control the rotor currents. This means that when the rotor voltage becomes limited by the actuation of the protection, it is not possible to control the current as desired. This implies that a voltage dip can cause large induced voltages or currents in the rotor circuit. If the rotor current or the internal rotor voltage becomes too high due to a line fault (e.g., a short circuit), it is necessary to have a protection device that short circuits the rotor circuit (i.e., a crowbar), and thereby protects the inverter from overcurrents and the rotor of the generator from overvoltages.

In this work, the converter is protected by a "crowbar," as shown in Fig. 7. To represent the operation of the crowbar, the model deactivates the converters upon the detection of rotor current magnitude above the current protection limit. A rotor current limit of $i_{r}=1.5$ p.u. was implemented in the model. By deactivating the converters, the rotor windings of the DFIG are short-circuited during the fault. When the converter blocks, a signal is sent to the switchgear between the stator and the grid and finally the switch disconnects the stator.

\section{NUMERICAL RESULTS}

The electrical grid used in this investigation to evaluate the dynamic behavior of the DFIG is similar to the one described in [12]. The original system of this reference was modified to include a wind farm composed of 38 turbines of $660 \mathrm{~kW}$ each. The dynamic model of the wind farm includes an equivalent model of its internal electric network; thus, an equivalent wind generator at $690 \mathrm{~V}$ is considered. The wind farm is connected to the grid through $0.69-\mathrm{kV} / 13.8-\mathrm{kV}$ transformers. The static capacitor bank reinforces the excitation of the wind generators when cage generators are used.

Besides the wind farm generation, a conventional diesel electric plant with a synchronous generator of 35 MVA connected to bus 3 and an infinite bus bar deliver power to the electric load of this system, as viewed in Fig. 8. The model parameters of the speed and voltage regulators and synchronous generators of the diesel units were obtained from [8] and [15]. The main characteristics of the asynchronous generators and wind turbines are in the Appendix. 


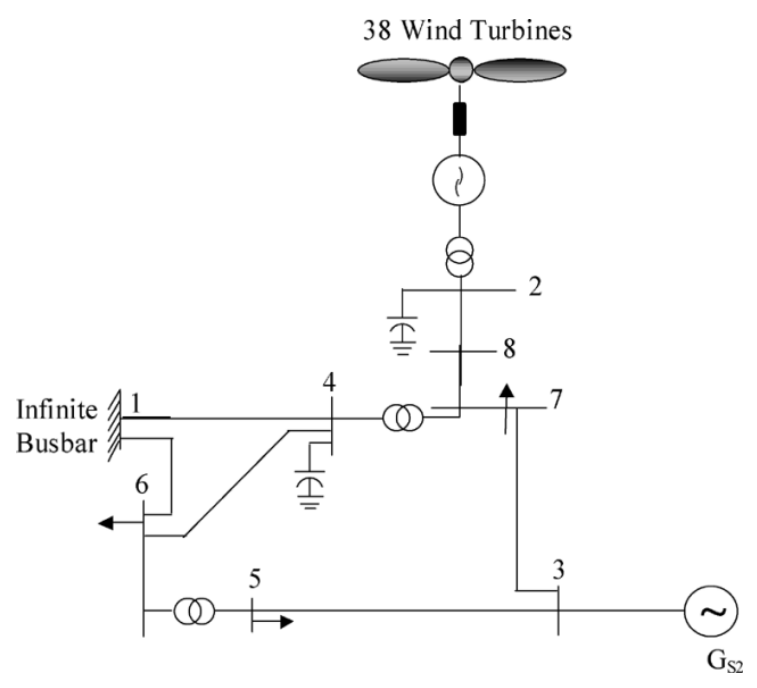

Fig. 8. Electrical grid with wind and diesel generation.

A subtransient $d-q$ level model is adopted here to represent the synchronous generator. In this model, the generator rotor consists of three windings. A field and a damper winding are considered on the direct axis in order to take into account the transient and subtransient behavior, respectively, in this axis. On the quadrature axis, a damper winding is considered having subtransient time constant. With this model, both subtransient and transient phenomena are clearly available [11]. The equivalent automatic voltage regulator used is an IEEE Type 1 model. The equivalent primary machine of the synchronous generator and its speed governor are first-order models with proportional/ integral frequency control [12], [16].

The simulations performed were selected in order to show how the DFIG can contribute to increase the global transient stability margin of the network. With this objective, two critical faults (three-phase short circuit) are simulated on the grid; one near the conventional diesel generator and another near the wind farm. In this sense, the transient behavior of the conventional synchronous generator $G_{s 2}$ is evaluated when both the DFIG and the fixed speed induction generators are alternately connected at bus 2 . The two models developed to represent the DFIG rotor converters connected to the grid were used and their performance was assessed comparatively. Here, the most relevant variables related to transient stability as phase angle of the synchronous machine, rotor current of the DFIG, rotor speed, and reactive power were compared.

\section{A. Fault Near the Conventional Synchronous Generator}

A very common indicator of transient stability of synchronous generators is the critical clearing time (CCT), which is defined as the maximum duration of the fault, which will not lead to loss of synchronism of the generators. For the sample system presented, the maximum critical clearing time of the synchronous machine when cage generators are integrated in the network corresponds to $445 \mathrm{~ms}$, whereas in the case where DFIG is adopted, this time increases to $500 \mathrm{~ms}$.

Fig. 9 illustrates the rotor phase angle of the synchronous generator $\mathrm{G}_{\mathrm{s} 2}$, in degrees, when a three-phase short circuit with duration of $450 \mathrm{~ms}$ is applied at instant $t=1 \mathrm{~s}$ near bus 3 . The syn-

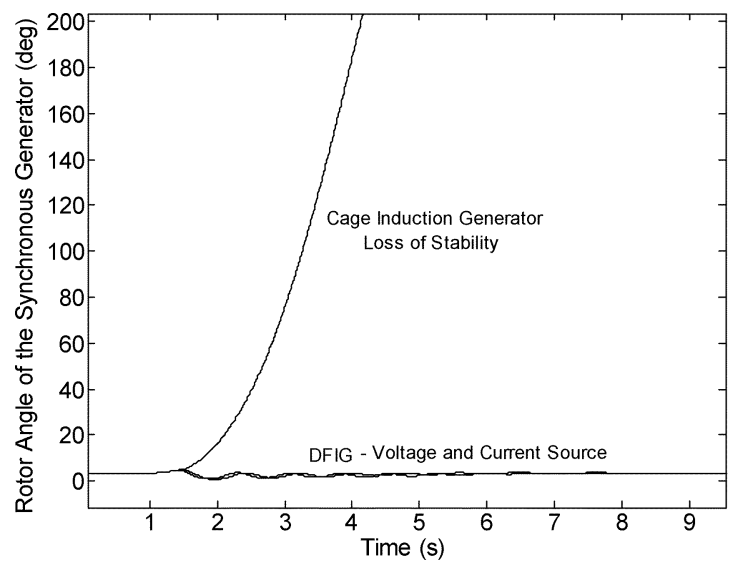

Fig. 9. Rotor angle of the synchronous generator.

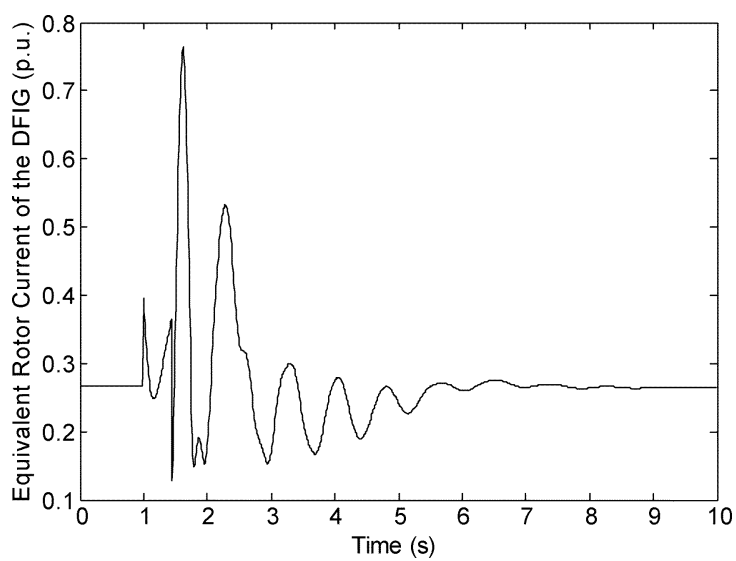

Fig. 10. Rotor current transient behavior of the DFIG.

chronous generator drops out of phase in the case where squirrel cage generators are adopted. On the other hand, when the DFIG is used, the synchronous generator maintains the stability. The simulations are made in order to find the maximum possible critical fault times for the two configurations of induction machines in the electrical grid. After this limit, the synchronous machine speed will increase rapidly due to loss of synchronism. This criterion is used as definition of the stability margin. The simulation indicates that the DFIG represents a benefit to the system by increasing the transient stability margin of the conventional synchronous generator.

Fig. 10 shows the resulting current in the rotor circuit of the DFIG. Due to the fact that the current is within the limits of the rotor protection, the induction generator is kept on the grid. It has a beneficial effect on transient stability of the other machines because the rotor speed control causes an increase in DFIG power output, which improves the balance between the powers, supplied and consumed, in the system and contributes to reduction of synchronous generator acceleration during the fault. After the fault, by action of the controllers and to counteract the active power deviation, the rotor current varies and finally goes to the previous value before the fault.

The rotor speed of the asynchronous machines for the same fault is shown in Fig. 11. For the cage generator without converter control, it is observed that the imbalance between mechanical and EM torque feeds the acceleration process of the 


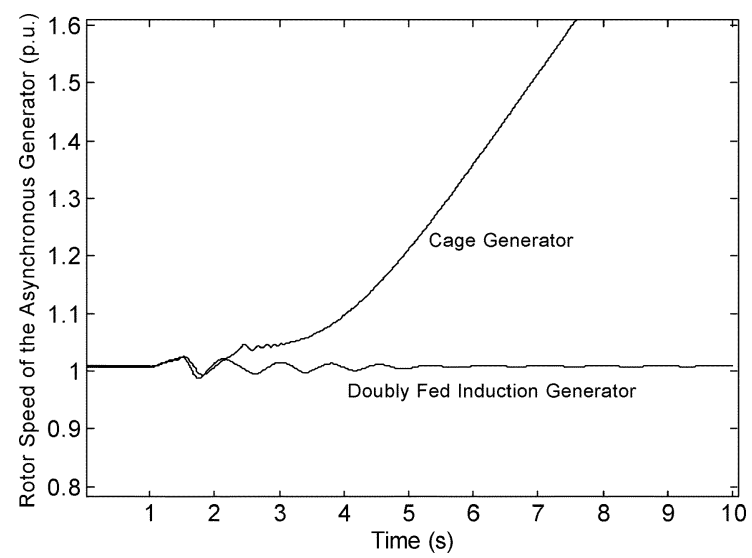

Fig. 11. Rotor speed transient behavior of the asynchronous generators.

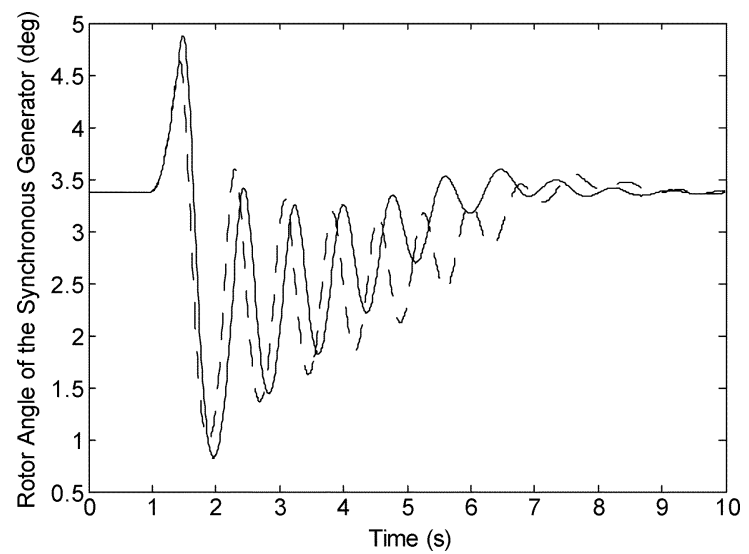

Fig. 12. Rotor angle transient behavior of the synchronous generator.

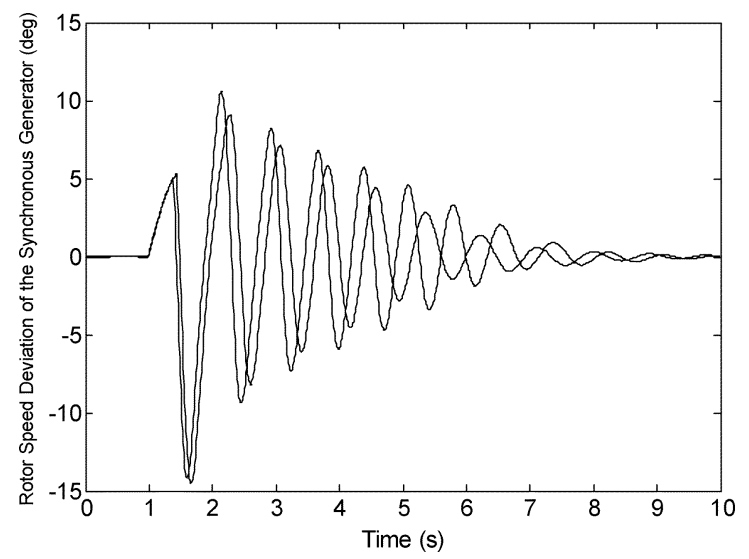

Fig. 13. Rotor speed transient behavior of the synchronous generator.

turbine resulting in loss of stability of the generator. On the contrary, for the DFIG, the converter controls the $q$-axis rotor currents in order to produce the specified electrical power to the system. By generating compensated rotor currents, energy is extracted from the rotor and forced into the network contributing to the balance between the EM and mechanical torque of the machine and consequently to maintain stability.

Figs. 12 and 13 emphasize the transient behavior of rotor phase angle and rotor speed of the synchronous machine regarding the case where DFIG is used. The curves of Fig. 12 correspond to an amplification of the rotor angle behavior from the

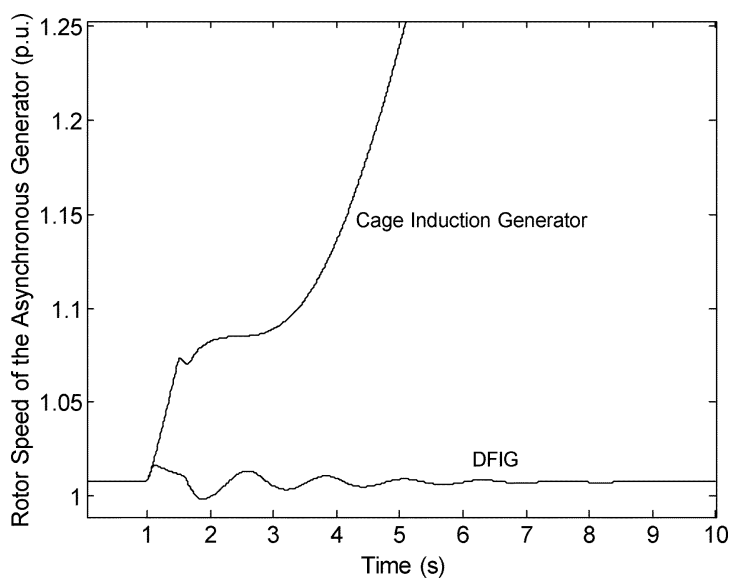

Fig. 14. Rotor speed transient behavior of the asynchronous generator.

Fig. 9, namely during the first postfault seconds, specifically regarding the DFIG. In the two figures, the solid line corresponds to the voltage source model (full model) and the dotted line to the current source model. From the results, it can be concluded that the differences between the two models are rather small in terms of steady-state value, overshoot, and time required to reach a new steady state.

From these simulations, one can conclude that both models were able to provide similar results in terms of the system dynamic behavior and its stability margins. Since the current source modeling leads to a less demanding approach in terms of computational effort, one can accept it for DFIG modeling in dynamic and transient stability studies. In fact, such a decision in DFIG modeling simplifies the representation of these generators enabling the use of larger simulation time steps since short-time constants from the rotor have been eliminated.

\section{B. Fault Near the Wind Farm}

The influence of the wind generators in the transient stability margin of conventional synchronous generators was also verified with another fault simulation in which a three-phase short circuit near the wind generation bus 2 (electrically far from the conventional synchronous generator) is applied at instant $\mathrm{t}=1 \mathrm{~s}$ lasting for $150 \mathrm{~ms}$. Line reclosure occurs at $\mathrm{t}=1.5 \mathrm{~s}$. Here, only the current source model is used to represent the rotor converters of the DFIG, since as concluded from the previous analysis, this model is accurate enough for the simulations purposes.

Fig. 14 shows the rotor speed behavior of the induction machines. It is clearly observed that the dynamic stability limits of the cage generator without converter control is exceeded. It is due to the fact that when a voltage dip reaches a wind generator (squirrel cage machine), the generated active power falls, while the mechanical power does not change; so the wind generator accelerates. After reclosure, the unbalance between mechanical and EM torque feeds the acceleration process of the turbine resulting in a continuous increase of the rotor speed generator.

As the rotor speed has increased, the active power tends to be higher than before the fault. But this also requires more current, which produces higher voltage drops in the lines and transformers and, therefore, the voltage does not recover as shown 


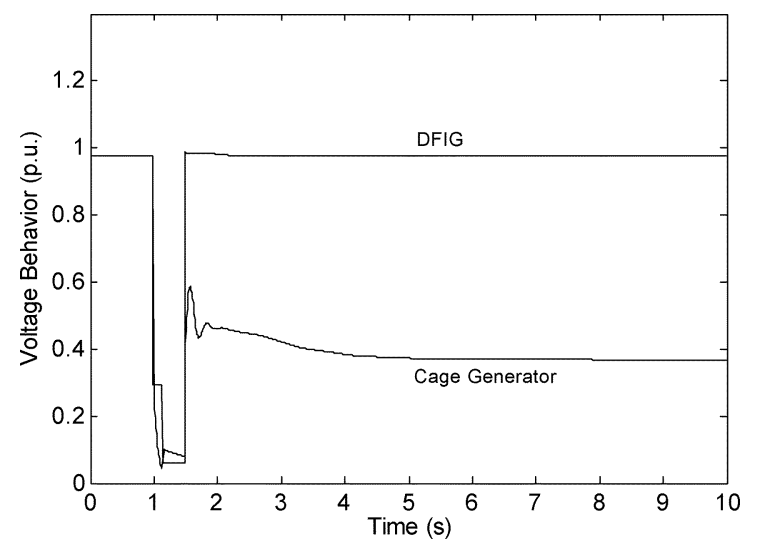

Fig. 15. Voltage behavior of the DFIG and cage generator.

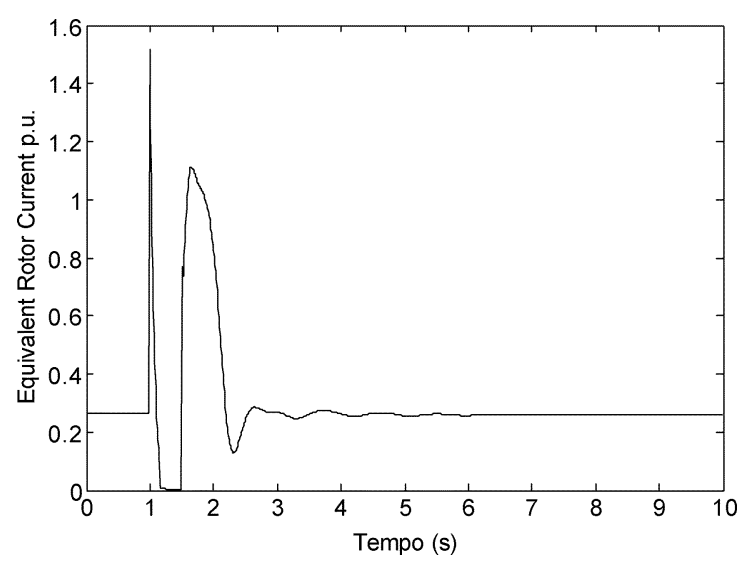

Fig. 16. DFIG equivalent rotor current.

in Fig. 15 regarding the case of fixed speed wind system. This is a greater disadvantage for these generators, since there is the possibility of de-excitation following occurrence of the network faults. On the other hand with the DFIG, the voltage recovers almost instantaneous after reclosure, which is assured by the very fast action of the controllers.

Fig. 16 shows the resulting current in the rotor circuit of the DFIG. The current limit of the rotor converter was exceeded. During the crowbar action, after the disconnection of the stator from the grid, the excitation is removed. After reclosure of the machine, the control loop aids to restore the current to the previous value. The large increment of the current after reclosure is given by the active power required to quickly counteract the speed deviation.

The terminal voltage controller based on the rotor excitation current $\left(i_{d r}\right)$ allows the recovery of reactive power consumed by the DFIG after reclosure of the machine as can be observed in Fig. 17. In this case, there are no extra static or dynamic reactive compensation demands for maintaining the short-term voltage stability of the wind farm. The positive influence in the reactive power behavior of the synchronous generator originating from control of the DFIG is clearly observed after the fault, where the reactive power returns to the previous value.

On the other hand, the use of fixed speed wind systems based on the cage induction generator increases the demand for reactive power necessary to maintain the dynamic voltage stability

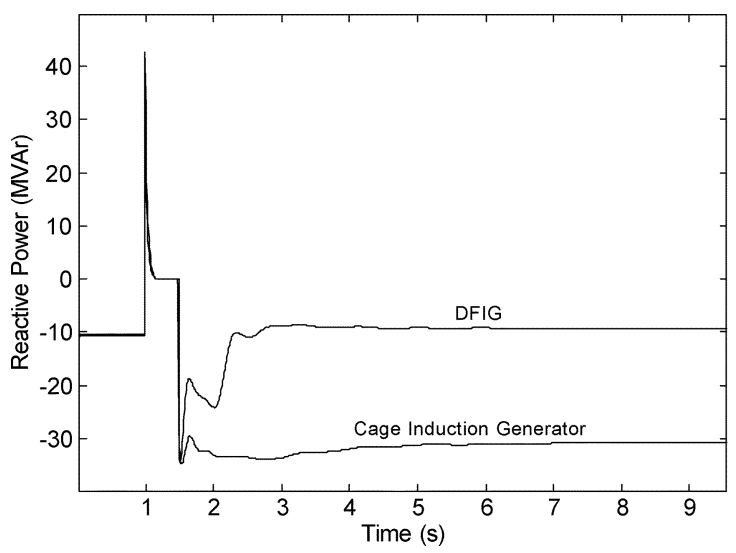

Fig. 17. Reactive power transient behavior of the asynchronous generators

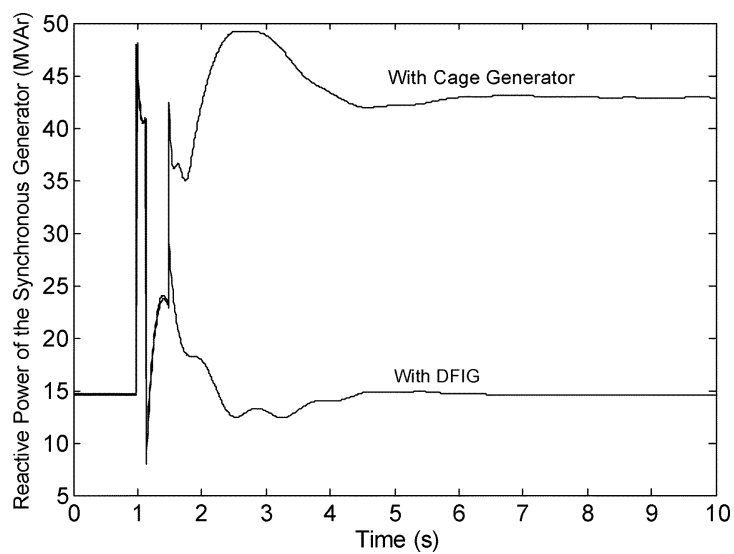

Fig. 18. Reactive power transient behavior at the synchronous generators.

at the terminals of the wind generators. The additional demand is met by the reactive power reserves carried by the synchronous generator as can be viewed in Fig. 18, in the case with cage generator. In this case, the power system is subject to a sudden transient of reactive power following the system contingency. This is a limiting fact of the fixed wind speed systems configuration that contributes to the decrease in transient stability margin of the power system, stressing the network due to increase in the reactive power losses in the lines ( $Q$ absorbed by a line increases rapidly for loads above impedance loading) [8], thereby causing a heavy reactive power demand on the grid that can lead to a low unacceptable voltage profile in a significant part of the system and then conducting to a voltage collapse of the network due to reduction of the reserves of reactive power.

\section{CONCLUSION}

In this paper, the transient stability margin of an electrical network, which employs variable-speed wind systems with adjustable speed generator DFIG, was compared with the case in which fixed speed wind systems with cage induction generators are used.

Due to the impossibility of achieving the rotor voltage to control the rotor currents in the case of voltage disturbances, it was necessary to employ a converter protection scheme on the DFIG. This protection was considered by a crowbar implementation on the rotor of the machine during a fault in the grid. By this 
procedure, the current controllers are deactivated and the rotor windings of the DFIG are short-circuited.

The main interest when modeling new technologies as DFIG in power system dynamic simulation software is the behavior of the converters. The model representing these subsystems should comply with the requirements resulting from the simplifications made in power system dynamics software. With this philosophy, two ways of modeling these converters were investigated and the very similarity of the transient stability margin provided by both demonstrate the possibility of adopting the most simple model (i.e., current source model to represent the integration of the DFIG in these studies).

The simulation results confirm the expectation that the transient stability of cage generators is poor. The situation becomes more severe with the increase of these machines in regions electrically far from synchronous generators. From the point of view of the network, the disconnection of cage generators following instability or the operation of pole slipping protection will impact the frequency control and the amount of reactive reserve required.

The results clearly show that the DFIG improves the shortterm postfault stability of the conventional generators in the network. The doubly fed machine is more robust than cage generators in the event of critical faults as a short circuit. The DFIG is able to keep the torque equilibrium, still maintaining the necessary transient stability margin of the electrical system. This, in turn, gives less speed deviation and better ability to control the network behavior.

The reduction in dynamic reactive compensation demands was also observed when using the DFIG, which helps to avoid other problems as voltage collapse in the power system. As a part of the term "ancillary systems," the DFIG may have an increasing market ahead. This is an important feature that must be considered in the choice of the wind system scheme to be integrated on strong or weak electrical grids.

\section{APPENDIX}

Induction generator: Index 1 corresponds to the stator parameters and 2 to the rotor parameters in per unit rated generator power $=660 \mathrm{~kW}$, rated voltage $=690 \mathrm{~V}$, rated generator slip $=2 \%, \mathrm{R} 1=0.0067, \mathrm{R} 2=0.0058$, $\mathrm{X} 2=0.0506, \mathrm{X} 1=0.03$, magnetic reactance $=2.31$, synchronous speed $=1500 \mathrm{r} / \mathrm{min}$, number of poles $=4$.

Parameters of wind turbine number of blades $=3$, rotor diameter $=44-\mathrm{m}$-rated speed $=14 \mathrm{~m} / \mathrm{s}$, relationship of gears $=55$, cut-in wind speed $=3 \mathrm{~m} / \mathrm{s}$, cutoff wind speed $=$ $25 \mathrm{~m} / \mathrm{s}$.

\section{ACKNOWLEDGMENT}

This work is the result of collaboration between the Power System Laboratory (LABSPOT) of the Federal University of Santa Catarina, the Nucleus of Energy, Systems and Communication (NESC) of the Federal University of Pará from Brazil, and INESC-Porto in Portugal.

\section{REFERENCES}

[1] N. Jenkins, J. B. Ekanayake, L. Holdsworth, and X. Wu, "Dynamic modeling of doubly fed induction generator wind turbines," IEEE Trans. Power Syst., vol. 18, pp. 803-809, May 2003.
[2] S. Muller, M. Deicke, and R. W. De Doncker, "Doubly fed induction generator systems for wind turbines," IEEE Ind. Applicat. Mag., vol. 8, pp. 26-33, May/June 2002.

[3] R. Pena, J. C. Clare, and G. M. Asher, "Doubly fed induction generator using back-to-back PWM converters and its application to variablespeed wind-energy generation," Proc. Inst. Elect. Eng., Elect. Power Applicat., vol. 143, no. 3, May 1996.

[4] P. Sørensen et al., Simulation of Interaction Between Wind Farm and Power System, Ris $\varnothing$ National Laboratory, Ris $\varnothing-\mathrm{R}-1281(\mathrm{EN})$, Roskilde, Denmark, Dec. 2001.

[5] S. Heier, Grid Integration of Wind Energy Conversion Systems. New York: Wiley, 1998.

[6] V. Akhmatov, H. Knudsen, and A. H. Nielsen, "Advanced simulation of windmills in the electric power supply," Elect. Power Energy Syst., vol. 22, pp. 421-434, 2000.

[7] M. V. A. Nunes, H. H. Zürn, and U. H. Bezerra, "Use of blade angle control to improve the voltage stability in the failure events," in Proc. Inst. Elect. Eng. 3rd Mediterranean Power Generation, Transmission, Distribution Energy Conversion Conf., Athens, Greece, Nov. 2002.

[8] P. Kundur, Power System Stability and Control. New York: McGrawHill, 1994.

[9] P. C. Krause, O. Wasynczuk, and S. D. Sudhoff, Analysis of Electric Machinery. New York: IEEE Press, 1994.

[10] A. Feijoo, J. Cidras, and C. Carrillo, "A third order model for the doubly-fed induction machine," Elect. Power Syst. Res., vol. 56, pp. 121-127, 2000.

[11] M. V. A. Nunes, H. H. Zürn, and U. H. Bezerra, "Transient stability margin of variable versus fixed speed wind systems in electrical grids," in Proc. IEEE Bologna Power Tech. Conf., Bologna, Italy, June 23-26, 2003.

[12] G. N. Kariniotakis and G. S. Stavrakakis, "A general simulation for the accurate assessment of isolated diesel-wind turbines interaction, part I: a general multimachine power system model," IEEE Trans. Energy Conversion, vol. 10, pp. 577-583, Sept. 1995.

[13] U. H. Bezerra, M. A. B. Amora, and A. M. Z. da Cunha, "Impacts in distribution grids due to the connection of distributed wind generation," in Proc. IEEE Porto Power Tech Conf., Sept. 2001, pp. 162-167.

[14] L. H. Hansen et al., Conceptual Survey of Generators and Power Electronics for Wind Turbines, Ris $\emptyset$ National Laboratory, Roskilde, Denmark, Dec. 2001.

[15] P. M. Anderson and A. A. Fouad, Analysis of Faulted Power Systems. Ames, Iowa: Iowa State Univ. Press, 1995.

[16] N. Jenkins, R. Allan, P. Crossley, D. Kirschen, and G. Strbac, Embedded Generation. London, U.K.: Inst. Elect. Eng., 2000.

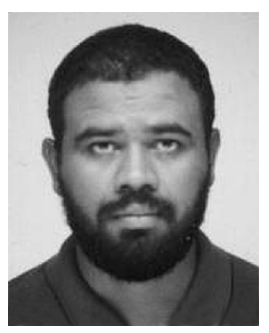

Marcus V. A. Nunes received the B.Sc. and M.S. degrees from the Federal University of Pará, Pará, Brazil, in 1994 and 1996, respectively. He is currently pursuing the Ph.D. degree on large-scale integration of wind generation into existing electric grids in the Power Systems Laboratory (LABSPOT) with the Federal University of Santa Catarina, Santa Catarina, Brazil.

Currently, he is an Assistant Professor with the Electrical and Computer Engineering Department at the Federal University of Pará, where he has been since 1997. His main research interests include power system dynamic analysis, electrical machines, and power-electronic and renewable energy generation, such as wind energy.

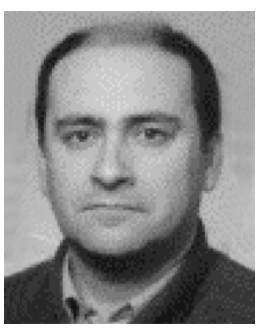

J. A. Peças Lopes (SM'94) received the electrical engineering degree and the Ph.D. degree in electrical engineering from the University of Porto, Porto, Portugal, in 1981 and 1988, respectively. He received the Aggregation degree from the University of Porto in 1996.

Currently, he is an Associate Professor with the Aggregation in the Department of Electrical Engineering with the Faculty of Engineering at the University of Porto. He is also co-Coordinator of the Power System Unit of the Institute of System and Computer Engineering (INESC) of Porto and in 1989, became Senior Researcher at INESC. 


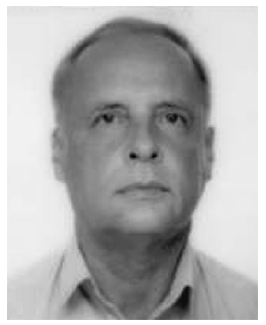

Hans Helmut Zürn (M'75) received the engenheiro mecânico-eletricista degree from the Federal University of Rio Grande do Sul, Porto Alegre, Brazil, in 1966. He received the M.Sc. degree from the University of Houston, Houston, TX, in 1969, and the Ph.D. degree from the University of Waterloo, Waterloo, ON, Canada, in 1976.

Currently, he is with the in the Department of Electrical Engineering, Faculty of the Federal University of Santa Catarina, Florianópolis, Brazil, where he has been since 1967. His current research interests include power systems operation and distributed generation modeling.

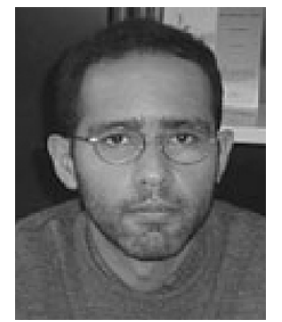

Rogério G. Almeida received the B.Sc. and M.Sc. degrees from the Federal University of Pará, Pará, Brazil, in 1996 and 1999, respectively. He is currently pursuing the Ph.D. degree on the effects of large technology on power system dynamics, namely, renewable energy generation.

His research is carried out at the Power System Unit of the Institute of System and Computer Engineering (INESC), Porto, Portugal. His main interests focus on power system dynamic analysis, electrical machines, and power electronics.

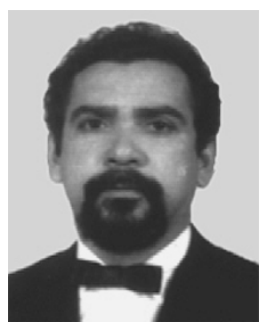

Ubiratan H. Bezerra received the B.Sc. degree in electrical engineering from the Federal University of Pará, Pará, Brazil, in 1976; the M.Sc. degree in electrical engineering from the Federal University of Itajubá, Itajubá, Brazil, in 1980; and the D.Sc. degree in electrical engineering from Federal University of Rio de Janeiro, Rio de Janeiro, Brazil, in 1988.

Currently, he is a Titular Professor with the Electrical and Computer Engineering Department at the Federal University of Pará. His research interests include power system dynamic security assessment, power quality, and renewable energy generation. 